\title{
O USO DO BRASÃO DAS ARMAS NACIONAIS NOS CATÁLOGOS DA PINACOTECA NA DÉCADA DE 1940
}

Jade Samara Piaia

Faal - Faculdade de Artes e Adm. de Limeira / Unicamp

jadepiaia@gmail.com

Edson do Prado Pfützenreuter

Unicamp

edson.reuter@iar.unicamp.br

Resumo: Este artigo traz uma análise da memória gráfica da Pinacoteca, a partir dos catálogos de obras, publicados na década de 1940. A Pinacoteca do Estado de São Paulo compreende o museu de arte mais antigo, e em pleno funcionamento até a atualidade, do estado de São Paulo. Grande parte da memória gráfica da instituição encontra-se preservada no acervo do Cedoc - Centro de Documentação e Memória da Pinacoteca - e compreende a fonte primária de dados deste artigo. Dentre os mais de cem anos de memória gráfica da Pinacoteca, fundada em 1905, foi definido um recorte temporal que compreende os catálogos de obras pertencentes ao acervo da instituição publicados na década de 1940. O objetivo é observar as influências dos aspectos históricos sobre a identidade visual dos catálogos da Pinacoteca, a partir de sua memória gráfica, com foco na cultura material preservada em acervo. O escopo compreende peças gráficas institucionais que apresentam a identificação da instituição. Neste artigo, foram analisados dois catálogos de obras publicados respectivamente nos anos de 1940 e 1942 pela Gráfica Paulista de João Bentivegna. Um levantamento das publicações da Gráfica Paulista, datadas do mesmo período, foi realizado e faz parte da análise. A partir das formas de identificação da Pinacoteca nestes catálogos, o objeto de estudo compreende a relação da identidade visual dos catálogos com os aspectos históricos da instituição, que a influenciaram ou que a identidade reflete em sua forma visual. A análise abrange a identificação da linguagem visual, das tecnologias gráficas empregadas e a relação com os períodos históricos vividos pela instituição e pelo campo gráfico na década de 1940 .

Palavras-chave: Memória gráfica; Pinacoteca; Identidade visual; Catálogo; Brasão das Armas Nacionais.

Abstract: This article presents an analysis of the graphics memory of the 'Pinacoteca', from the catalogs of works published in the 1940's The 'Pinacoteca do Estado de São Paulo' comprises the oldest art museum, and in full operation to the present, the state of São Paulo. Much of the graphics 
of the institution's memory is preserved in the collection Cedoc-Centre for Documentation and Memory 'Pinacoteca' - and comprises the primary source of data in this article. Among the over one hundred years of graphics memory the 'Pinacoteca', founded in 1905, one time frame has been set comprising the catalogs of works belonging to the institution's collection published in the 1940's. The goal is to observe the influences of the historical aspects of the visual identity catalogs of the 'Pinacoteca', from its graphics memory, with a focus on material culture preserved in the collection. The scope comprises institutional graphic pieces that present the identification of the institution. In this article we analyzed two catalogs of works published respectively in 1940 and 1942 by 'Gráfica Paulista de João Bentivegna'. A survey of publications 'Gráfica Paulista', dating from the same period, was carried out and is part of the analysis. From forms of identification of the 'Pinacoteca' in these catalogs, the object of study comprises the relationship of visual identity of catalogs with the historical aspects of the institution that influenced or that the identity reflected in its visual form. The analysis includes identification of visual language, the utilized graphics technologies and the relationship with the historical periods experienced by the institution and the graphic field in the 1940's.

Key words: Graphic memory; Pinacoteca; Visual identity; Catalog; National Coat of Arms.

\section{INTRODUÇÃO}

O termo "memória gráfica" vem sendo utilizado com mais frequência nos últimos dez anos e, em países de língua espanhola e na América Latina, está ligado a uma linha de estudos envolvendo artefatos visuais e impressos efêmeros, relacionados com uma identidade de design local, segundo Priscila Farias (2014). As pesquisas sobre "memória gráfica" constituem narrativas ligadas à história do design, em paralelo com campos de estudos já estabelecidos, como o da cultura visual, cultura impressa e a cultura material. $O$ estudo da memória gráfica estabelece um sentido de identidade local através de impressos gráficos e, enquanto campo de pesquisa, é considerado recente por Farias (2014).

Entende-se que a memória gráfica de um equipamento cultural pode, a princípio, ser preservada ao longo de suas publicações impressas. No caso da Pinacoteca, fazem parte da memória gráfica impressos como os catálogos de obras do acervo, catálogos de exposições, documentos institucionais, cartazes, convites e folhetos com a programação do museu.

As peças gráficas da Pinacoteca analisadas neste artigo pertencem ao Cedoc Centro de Documentação e Memória da Pinacoteca - entidade fundada em 2005, que coleta, organiza e disponibiliza a documentação histórica do museu (GOVERNO, et al., 2015 , p. 4). Uma extensa exposição compreendendo o acervo gráfico da Pinacoteca denominada '100 anos de edição gráfica da Pinacoteca do Estado: 1912-2012' (MARINGELLI; BEVILACQUA, 2013) ocorreu na Pinacoteca em 2013 e foi o ponto inicial de uma pesquisa mais ampla envolvendo a memória gráfica da instituição. 
O objetivo deste artigo consiste em traçar uma análise da cultura material envolvendo a memória gráfica da Pinacoteca do Estado de São Paulo, na modalidade estudo de caso, observando as influências dos aspectos históricos sobre a identidade visual dos catálogos da Pinacoteca datados da década de 1940. Para isto, foram consultados artigos de historiadores e pesquisadores do campo do design gráfico, que esboçam sobre a preservação da cultura material através de métodos aplicados em análises de artefatos de memória gráfica. O levantamento e análise das diferentes tipologias do acervo gráfico do Cedoc da Pinacoteca pode contribuir para a identificação de períodos, tendências estéticas e personagens da história gráfica paulistana.

\section{DESENVOLVIMENTO}

\subsection{Breve histórico da Pinacoteca até década de $\mathbf{1 9 4 0}$}

A Galeria de Pintura do Estado - Pinacoteca - foi instalada em uma das salas do edifício do então Liceu de Artes e Ofícios, sob responsabilidade do engenheiro Ramos de Azevedo. Inicialmente contava com 26 obras transferidas do eclético acervo do Museu Paulista, o único no estado até então, inaugurado em 1895 (CAMARGOS; MORAES, 2005, p. 18).

A conturbada década de 1930 fez com que, durante a Revolução Constitucionalista, a Pinacoteca fosse fechada em 1932 e o edifício do Liceu de Artes e Ofícios cedido aos combatentes. O prédio do Liceu, que já havia sido fechado por um mês em junho de 1924, durante a Revolução Tenentista (ARAUJO; CAMARGOS, 2007), permaneceu fechado durante um longo período, e a Pinacoteca teve suas obras dispersas por diversas instituições públicas. A coleção voltou a ser reunida na antiga sede da Imprensa Oficial do Estado, em um prédio localizado à Rua XI de Agosto, sob guarda da Escola de Belas Artes de São Paulo, reabrindo ao público em 1936 (CAMARGOS; MORAES, 2005, p. 21-23). Ainda em 1932 torna-se responsável pela Pinacoteca, sendo empossado oficialmente em 1936, o pintor Paulo Vergueiro Lopes de Leão, permanecendo até 1944 (AMARAL, 2006, p. 182).

No período inicial da década de 1940, a Pinacoteca funcionava ainda na sede localizada à Rua XI de Agosto. Houve uma oferta por parte do prefeito para a mudança da Pinacoteca para o Palácio das Indústrias, mas foi negada por Paulo Leão devido à alta incidência de poluição no local. O museu permaneceu em funcionamento na Rua XI de Agosto até que o edifício foi comprado pela prefeitura que pretendia demoli-lo para a criação de uma praça (ARAUJO; CAMARGOS, 2007).

O Estado adquiriu a posse do prédio do Liceu de Artes e Ofícios em 1944, quando o prédio foi destinado ao abrigo da Pinacoteca, que dividiria o espaço com o Liceu, a Escola de Belas Artes e com o Conselho de Orientação Artística. Neste período, o acervo do museu cresceu e ultrapassou a quantidade de mil obras. $\mathrm{O}$ artista plástico e pintor Túlio Mugnaini assume a direção da Pinacoteca em 1944, permanecendo na função até 1965 (CAMARGOS; MORAES, 2005, p. 25).

Em março de 1947 o acervo foi transferido para sua sede original na Rua Tiradentes, na Luz, e o museu reaberto ao público. O Liceu foi aos poucos sendo transferido para a sede na Rua Cantareira - as duas instituições permanecem até os dias de hoje nestes locais. Embora estivesse em uma sede própria, a Pinacoteca ainda dividia o espaço físico com a Escola de Belas Artes e o Conselho de Orientação Artística. A totalidade do espaço se daria somente muitos anos a frente. Neste período 
o acervo foi enriquecido com alguns lotes de obras vindos do Museu Paulista, incluindo as de autoria de Almeida Júnior. No ano seguinte, o Conselho de Orientação Artística ao qual a Pinacoteca era subordinada foi extinto e a Pinacoteca passou a ser subordinada à Secretaria do Governo (CAMARGOS; MORAES, 2005, p. 26), fato que viria refletir em muitas das próximas publicações dos catálogos da Pinacoteca.

Modificando o cenário artístico paulistano, ainda na década de 1940, São Paulo passou a contar com mais dois museus. O Masp ${ }^{1}$ - Museu de Arte de São Paulo - foi inaugurado em 1947 por Assis Chateaubriand. Trazia obras de artistas internacionais, provindas da Europa, adquiridas no pós-guerra, com auxílio curatorial de Pietro Maria Bardi. Além do novo acervo, não visto anteriormente por aqui, promove exposições e passa a ter uma atuação multidisciplinar pioneira, oferecendo diversos tipos de atividades e cursos nos anos seguintes. Em seguida, em 1948, o MAM - Museu de Arte Moderna - foi fundado por Francisco Matarazzo Sobrinho, com importante atuação de sua esposa Yolanda Penteado (CAMARGOS; MORAES, 2005, p. 27). Trouxe obras abstratas de artistas europeus em sua exposição inaugural. São Paulo vivia no fim da década de 1940 uma grande efervescência que movimentava o setor cultural, o qual a Pinacoteca parecia não acompanhar.

\subsection{Métodos de análise aplicados}

Foram consultados artigos de historiadores e pesquisadores do campo do design gráfico que tratam de métodos aplicados em análises de artefatos de memória gráfica. Publicações como Lima \& Michelon (2010) referenciaram o modo de categorização e classificação dos dados; Aragão et al. (2010); Lima et al. (2012); e Wille et al. (2010) auxiliaram no modo de olhar os objetos em questão. Outras publicações como Tonini et al. (2010) e Salomon et al. (2009) nortearam a criação de um formulário a fim de auxiliar na coleta e organização de dados, bem como na análise dos mesmos.

O formulário elaborado objetivou otimizar a caracterização visual das peças gráficas, trouxe questões estéticas e tipográficas, de produção gráfica; relacionadas à assinatura visual que compreende a nomenclatura e a identificação visual da instituição; compilação dos dados ligados aos agentes gráficos envolvidos, editoras, gráficas e designers; entre outras informações pertinentes.

As questões abordaram: tipologia da peça gráfica; data do material; tipo de papel; tecnologia de impressão gráfica; cores; tamanho da peça; proporção da assinatura visual da instituição; nomenclatura da instituição; classificação tipográfica relacionada à assinatura visual: quanto ao uso ortográfico, tamanho das letras, disposição das palavras, alinhamento, inclinação, característica da família, peso, propriedades visuais; a assinatura visual em convivência com outros símbolos; posicionamento vertical e horizontal na peça gráfica; presença de elementos decorativos na peça gráfica; interação dos elementos decorativos com a assinatura visual; características e organização dos elementos decorativos; e a presença de imagens fotográficas e as respectivas características visuais das mesmas, quando houver.

O formulário foi desenvolvido dentro da plataforma de documentos Google Drive e preenchido on-line (PIAIA, 2016). As respostas foram automaticamente

\footnotetext{
${ }^{1}$ O Masp foi inaugurado em outubro de 1947 e funcionava na sede dos Diários Associados, à Rua 7 de Abril, São Paulo (CAMARGOS; MORAES, 2005, p. 27).
} 
tabuladas em uma planilha, facilitando a identificação de semelhanças e ressaltando os dados divergentes encontrados nos materiais gráficos.

A estruturação da análise gráfica parte dos propósitos de Twyman (1979), que distingue três grandes grupos de elementos da linguagem gráfica: o grupo dos elementos pictóricos, os elementos verbais e os esquemáticos. Também foram observadas na análise gráfica (VILLAS-BOAS, 2009) os formatos e medidas das peças gráficas, a estrutura organizacional, a mancha gráfica e a organização dos elementos. A presença de outros símbolos ou marcas junto à assinatura gráfica, o posicionamento da assinatura na peça gráfica, presença, interação e características dos elementos esquemáticos, bem como a presença de elementos pictóricos também foram observados.

Neste artigo são analisados dois catálogos da Pinacoteca, publicados durante a década de 1940, enfatizando o uso de um símbolo nacional, o Brasão das Armas Nacionais.

\subsection{As capas dos catálogos de 1940 e 1942: o uso da tipografia e do brasão das Armas Nacionais}

Com formato e configuração gráfica diferenciados dos catálogos publicados anteriormente, predomina nas capas dos catálogos da Pinacoteca da década de 1940 a utilização do brasão das Armas Nacionais. Pela primeira vez o catálogo continha no miolo, além da listagem das obras, algumas poucas imagens de obras de arte, impressas em preto e branco através de retículas. As edições anteriores continham apenas a listagem textual das obras do acervo, separadas por tipo de coleção, incluindo informações como numeração, autor e título.

Cabe mencionar que a Pinacoteca possui publicações de catálogos datadas anteriormente às da década de 1940, objetos de estudo deste artigo, respectivamente nos anos de 1912, 1914, 1917, 1921, 1926 (PIAIA, 2015) e 1938.

A estrutura física dos dois catálogos publicados respectivamente em 1940 e 1942 é bastante semelhante. O formato físico da peça compreende $11,5 \times 15,5 \mathrm{~cm}$ aproximadamente. Os elementos gráficos são compostos de duas bordas lineares finas que contornam a capa, com uma pequena diferença de espessura entre elas, o brasão das armas do Brasil e o conjunto de informações. A impressão se dá em apenas 1 cor, utilizando o preto como cor de impressão.

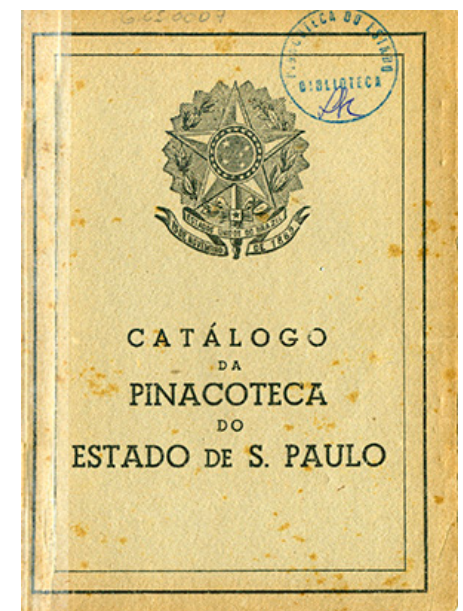

Figura 1 Catálogo 1940 - Catálogo da Pinacoteca do Estado de S. Paulo - Gráfica Paulista João

Bentivegna, São Paulo. Original escaneado. Fonte: Acervo Cedoc /Pinacoteca do Estado de São Paulo. 


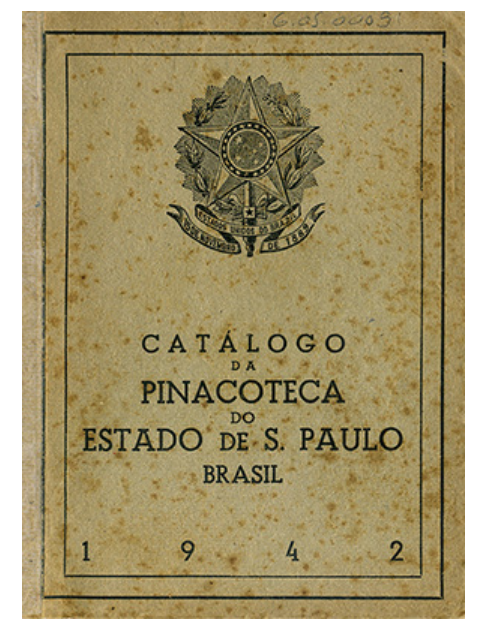

Figura 2 Catálogo 1942 - Catálogo da Pinacoteca do Estado de S. Paulo, Brasil, 1942 - Gráfica Paulista João Bentivegna, São Paulo. Original escaneado.

Fonte: Acervo Cedoc /Pinacoteca do Estado de São Paulo.

As informações constantes na capa do catálogo de 1940, centralizadas na metade inferior da capa são "Catálogo / da / Pinacoteca / do / Estado de S. Paulo". O texto é grafado em maiúsculas, com o uso de versaletes nas palavras "da / do / de". A diferença para a capa do catálogo de 1942 é que esta traz a palavra "Brasil" complementando o bloco de informações e o ano "1942", bastante espacejado entre os números, no rodapé. A tipografia com serifa quadrada em peso semibold rompe com o estilo tipográfico utilizado anteriormente nas capas dos catálogos. A assinatura da Pinacoteca aparece aplicada e integra a composição do título da publicação, com um certo destaque de tamanho em relação às demais informações textuais.

O brasão das Armas Nacionais aparece centralizado na metade superior da capa, em posição e tamanho de destaque. Foi utilizada a versão a traço para impressão monocromática do brasão das Armas Nacionais, que difere esteticamente em relação ao preenchimento da versão em cores.

Importante ressaltar que o brasão das Armas Nacionais utilizado nas capas dos catálogos da Pinacoteca citados (1940 e 1942) utilizavam o descritivo "Estados Unidos do Brazil", ainda grafado com " $z$ ", como na versão original de 1889 . Houve uma mudança significativa em uma atualização deste brasão, publicada através da lei $n^{\circ}$ 5.443 , de 28 de maio de 1968, cujo descritivo ao centro passou a ser "República Federativa do Brasil" (BRASIL, 1968).

Nas capas dos catálogos da Pinacoteca de 1940 e 1942 em que o brasão das Armas Nacionais figura, sua reprodução ocupa posição de destaque, isolado na parte superior, conforme demandam suas regras de uso. O brasão das Armas Nacionais não pode ser posicionado em conjunto com outras armas ou brasões em menor tamanho e devem ocupar posição de honra quando utilizada, segundo o capítulo IV, art. 27 (A BANDEIRA, 1970, p. 22). Nestes catálogos, a versão do brasão das Armas Nacionais reproduzida graficamente corresponde visualmente a uma estrutura muito próxima à versão original de 1889.

\subsection{Símbolo nacional: o brasão das Armas Nacionais}

O brasão das Armas Nacionais se configura um símbolo nacional, juntamente com a Bandeira, o Hino e o Selo Nacional. Foi instituído pelo artigo 8, decreto no 4 de 
19 de novembro de 1889 (A BANDEIRA, 1970). Encomendado pelo chefe do Governo Provisório, Marechal Deodoro da Fonseca, o brasão das Armas Nacionais, também denominado brasão da República, foi idealizado pelo engenheiro alemão Artur Sauer. Sauer vivia no Rio de Janeiro, onde atuava como técnico e sócio do famoso estabelecimento gráfico Casa Laemmert (LUZ, 1999).

Antigo oficial do exército prussiano, Sauer viera ao Brasil a convite de seus compatriotas Eduardo e Henrique Laemmert ${ }^{2}$, tornando-se sócio dos dois. Com o advento da República, Sauer incumbiu o seu mestre de oficina de fazer um desenho das armas para oferecê-lo ao Governo Provisório; para isto, instruiu seu empregado, Luís Grüder, como ele, desenhista. Terminado o projeto, levou-o ao Marechal Deodoro da Fonseca, em sua casa no Campo de Sant'Ana. Deodoro aprovou e comentou que 'o gládio representava a espada militar que proclamara a República' (LUZ, 1999).

A configuração visual do brasão das Armas Nacionais segue a descrição abaixo:

A feitura das Armas Nacionais deve obedecer à proporção de quinze de altura por quatorze de largura, e atender às seguintes disposições:

I - O escudo redondo será assim constituído: em campo de blau, cinco estrelas de prata, formando a constelação Cruzeiro do Sul; bordadura do campo perfilada de ouro, carregada de vinte estrelas de prata.

II - O escudo ficará pousado numa estrela partida-gironada, de 10 (dez) peças de sinopla e ouro, bordada de duas tiras, a interior de goles e a exterior de ouro.

III - O todo brocante sobre uma espada, em pala, empunhada de ouro, guardas de blau, salvo a parte do centro, que é de goles e carregada de uma estrela de prata, figurará sobre uma coroa formada de um ramo de café frutificado, à destra, e de outro de fumo florido, à sinistra, ambos da própria cor, atados de blau, ficando o conjunto sobre um resplendor de ouro, cujos contornos formam uma estrela de vinte pontas.

IV - Em listel, de blau, brocante sobre os punhos da espada, inscrever-se-á em ouro a legenda Estados Unidos do Brasil no centro, e ainda as expressões: 15 de novembro, na extremidade destra e as expressões: de 1889, na sinistra. (A BANDEIRA, 1970, p. 16)

O brasão estampado nas capas dos catálogos analisados compreende uma única cor, reproduzido através de um clichê em metal e impresso em tinta preta sobre papel branco. Nesta versão monocromática cada cor originalmente atribuída ao brasão foi substituída por uma hachura equivalente, segundo as leis da heráldica (LUZ, 1999), através das quais a direção e a inclinação das hachuras funciona como um código, relacionado a cada coloração do esmalte original.

Um problema recorrente em diversos símbolos, como no caso do brasão das Armas Nacionais, é a descaracterização de sua composição visual à medida em que é

\footnotetext{
${ }^{2}$ Foram encontradas em outras publicações referências dos nomes dos sócios como Eduard Laemmert e Heinrich Laemmert, que foram posteriormente traduzidos. Eduard fundou a Livraria Universal e posteriormente em sociedade com Heinrich a E. \& H. Laemmert - mercadores de livros e de música, também fundaram a Typographia Universal com importantes publicações gráficas no Rio de Janeiro. Em uma segunda geração, em 1891 a sociedade incluía outros nomes como Gustave Massow (genro do recém falecido Henrich), Edgon Widmann Laemmert (diretores da livraria) e Arthur Sauer (diretor da oficina tipográfica), sob a denominação de Laemmert \& Cia. (HALLEWEL, 2005, p. 232-248).
} 
reproduzido. Luz (1999) nos lembra que distorções gráficas relacionadas ao tamanho e ao desenho dos elementos que compõe o brasão, bem como aos padrões da heráldica para reprodução monocromática através de hachuras, equivalentes às colorações originais, podem ser observadas, incluindo versões despojadas das hachuras, e ainda, variação da tipografia, do tamanho e da distribuição das informações em texto na área específica.

Com relação às normas de reprodução técnica do brasão das Armas Nacionais apenas foram citadas as proporções de quinze de altura por quatorze (centímetros) de largura e a referência à imagem do brasão. Em uma tentativa de ensino do desenho técnico para fins de reprodução do brasão, o autor Milton Luz (1999, p. 117-126) faz passo a passo a reconstrução modular de uma versão atualizada do desenho do brasão.

\section{ANEXON. 9 \\ DESENHO DAS CONVENÇOES HERALDICAS DAS ARMAS NACIONAIS}

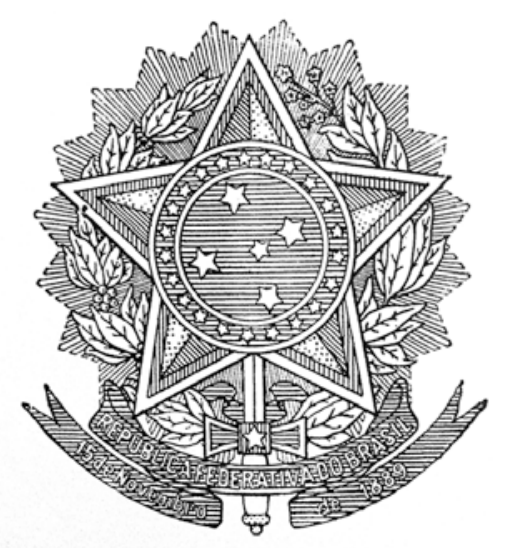

Figura 3 Desenho das convenções heráldicas das Armas Nacionais. Versão monocromática, segundo convenções heráldicas, para equivalência de cores através de hachuras.

Fonte: A BANDEIRA, 1970, p. 234.

Segundo a seção III, art. 20 da Lei no 5.443 (BRASIL, 1968), o uso das Armas Nacionais é obrigatório no palácio e residência da presidência, Câmara dos Deputados, no Senado Federal, no Supremo Tribunal Federal, nos Tribunais Superiores, nos palácios dos governos estaduais e nas prefeituras municipais, bem como em edifícios, repartições públicas e escolas públicas; nos quartéis das forças federais e policiais, bem como em armamentos; e ainda "nos papéis e expediente das repartições públicas e nas publicações oficiais" (A BANDEIRA, 1970). O uso dos brasões estaduais foi suspenso pela Constituição do Estado Novo - regime político que vigorou no país entre 1937 e 1945 - outorgada por Getúlio Vargas em 1937, na tentativa de impor somente o uso dos símbolos nacionais (FEDERICI, 1980). 

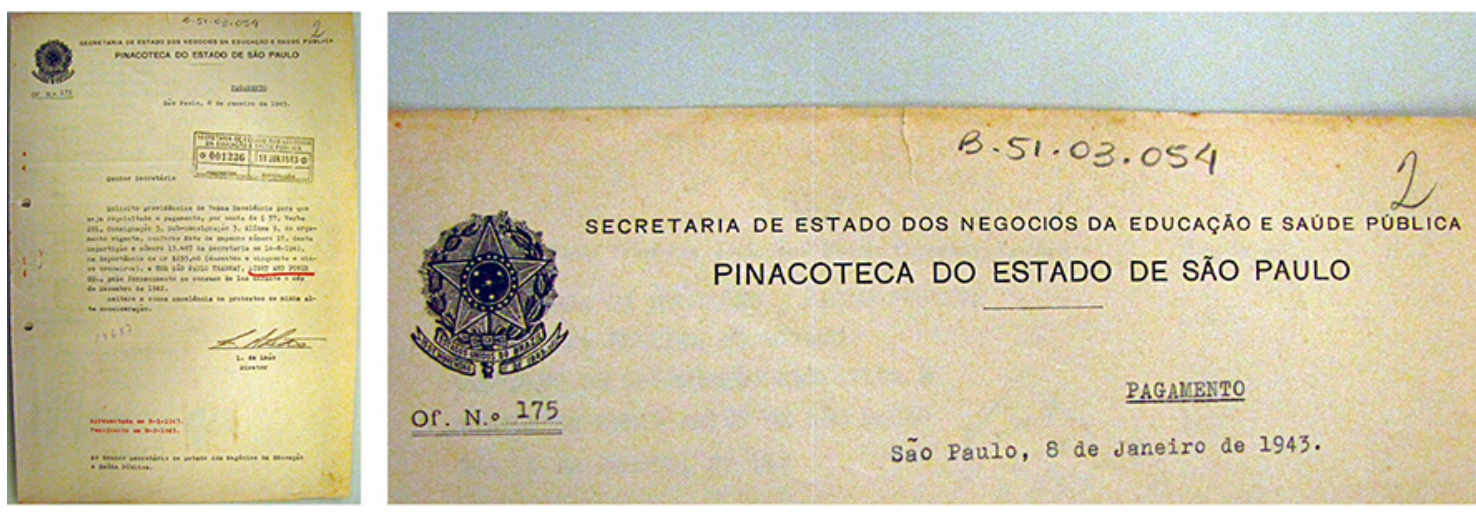

Figura 4 Documento timbrado, 1943 - Secretaria de Estado dos Negócios da Educação e Saúde Pública, Pinacoteca do Estado de São Paulo. Original fotografado.

Acervo Cedoc / Pinacoteca do Estado de São Paulo.

Cabe pontuar que o brasão das Armas Nacionais estampava ainda os documentos institucionais da Pinacoteca impressos no mesmo período. Neste papel timbrado datado de 1943 a assinatura gráfica da "Pinacoteca do Estado de São Paulo" aparece subordinada à "Secretaria de Estado dos Negócios da Educação e Saúde Pública" no cabeçalho. O cabeçalho é composto pelos elementos textuais em conjunto com o brasão das Armas Nacionais, posicionado no canto superior esquerdo, na versão a traço para impressão monocromática. Embora exista a semelhança no uso do brasão, cada peça gráfica têm suas próprias características.

O papel timbrado é mais sintético em relação aos catálogos, utiliza tipografias sem serifa nos elementos textuais e uma hierarquia dada pelo tamanho dos textos, conferindo importância à assinatura da Pinacoteca, composta em uma única linha. Não se sabe qual gráfica imprimiu este papel timbrado por não constar sua assinatura impressa.

O clichê em metal do brasão que compôs a capa dos catálogos da Pinacoteca de 1940 e 1942 foi possivelmente confeccionado pela gráfica que assina os materiais, ou por alguma clicheria parceira. Quem assina a composição e impressão dos catálogos é a Gráfica Paulista de João Bentivegna que, responsável pelas características estéticas dos catálogos, configura um ponto importante e que merece atenção nesta análise envolvendo a memória gráfica da Pinacoteca.

\subsection{Os impressos da Gráfica Paulista de João Bentivegna}

Os dois catálogos da Pinacoteca publicados respectivamente em 1940 e 1942 foram compostos e impressos na Gráfica Paulista, conforme a inscrição na penúltima página do catálogo de 1940 "Composto e impresso na Gráfica Paulista de João Bentivegna / Rua Silveira Martins, 252 / Telef. 2-3417 - S. Paulo", e ainda apresentam a marca da gráfica e seu endereço na quarta capa dos dois catálogos. 

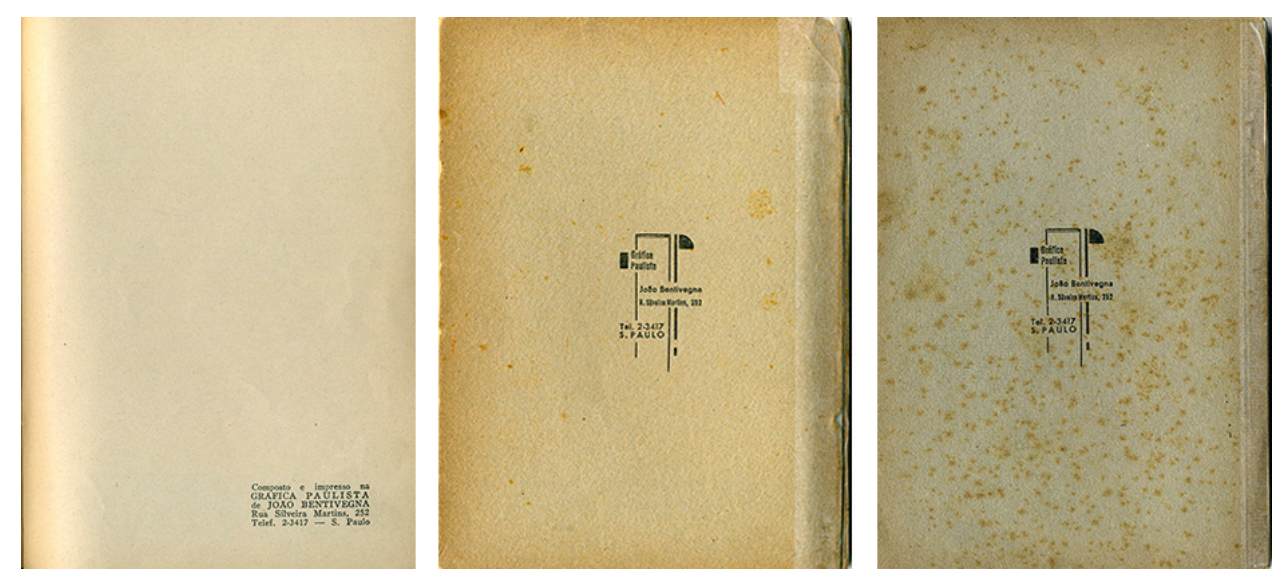

Figura 5 Catálogo 1940: página 85 (à esquerda) traz a descrição de quem compôs e imprimiu o material e na quarta capa (ao centro) traz a marca da Gráfica Paulista de João Bentivegna. Catálogo 1942: quarta capa (à direita) com a marca da Gráfica Paulista de João Bentivegna. Originais escaneados.

Fonte: Acervo Cedoc /Pinacoteca do Estado de São Paulo.

A assinatura visual da Gráfica Paulista na quarta capa dos catálogos é composta pelo logotipo da gráfica e alguns ornamentos geométricos lineares. A estrutura dos ornamentos lineares envolvem o nome da gráfica, o nome do proprietário João Bentivegna, o endereço, o número de telefone e a cidade, em uma mesma estrutura visual. Sabe-se que a "Indústria Gráfica de Bentivegna" foi fundada na década de 1920 e especializou-se na publicação de revistas (GORDINHO, 1991, p. 67).

O setor gráfico estava em expansão e em 1937 o número de tipografias no país ultrapassava 2 mil (GORDINHO, 1991, p. 69). Polarizando a produção gráfica, São Paulo se configurava um centro editorial com mais de quatrocentas gráficas em 1942, incluindo tipografias, litografias e clicherias (GORDINHO, 1991, p. 67).

Foram encontradas algumas publicações de Bentivegna datadas das décadas de 1940 e $1950^{3}$, períodos em que foi possível constatar uma atuação para o Governo do Estado além de publicações de livros em geral.
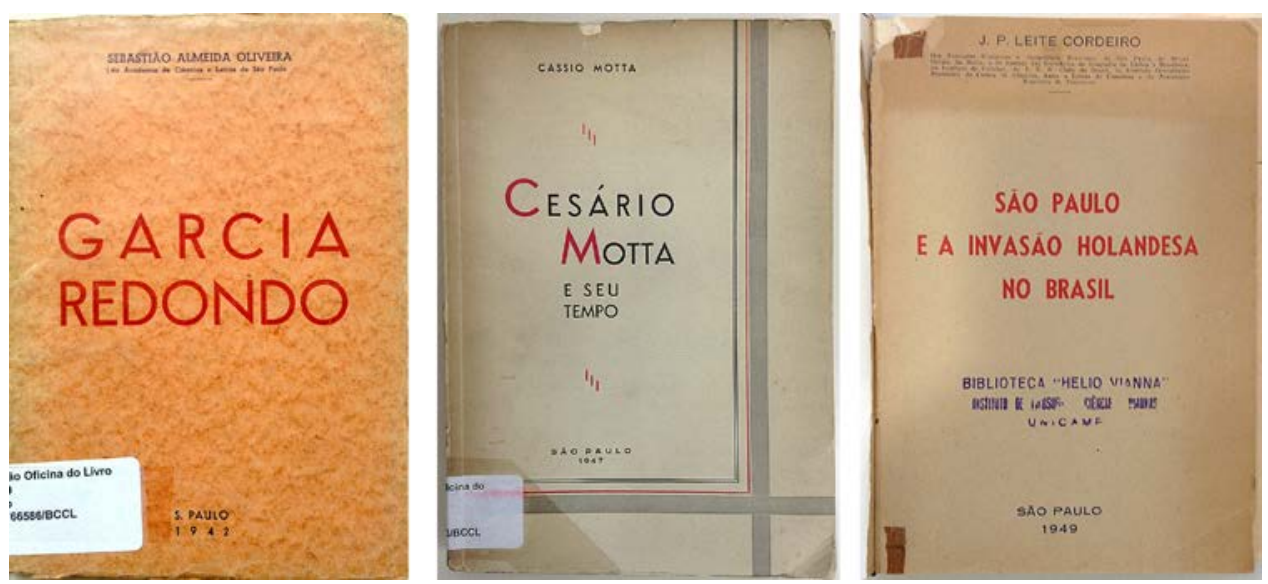

Figura 6 Capas de livros publicados pela Gráfica Paulista de João Bentivegna. “Garcia Redondo”, 1942. Fonte: Acervo de coleções Especiais e Obras Raras / Biblioteca Central César Lattes, Unicamp (não catalogado, 2015). “Cesario Motta e seu tempo”, 1947. Fonte: Coleção Oficina do Livro: Acervo de

\footnotetext{
3 "Documentos interessantes para a história e costumes de São Paulo", 1954. Fonte: Centro de Memória da Unicamp. "Catálogo dos documentos sobre São Paulo existentes no arquivo do Instituto Histórico e Geográfico Brasileiro", 1954. Fonte: Coleção Peter Eisenberg: Acervo de coleções Especiais e Obras Raras / Biblioteca Central César Lattes, Unicamp.
} 
coleções Especiais e Obras Raras / Biblioteca Central César Lattes, Unicamp. "São Paulo e a invasão holandesa no Brasil", 1949. Fonte: Acervo da Biblioteca Octávio lanni / Instituto de Filosofia e Ciências Humanas, Unicamp.

Nas amostras de capas das publicações assinadas por Bentivegna na década de 1940 são encontradas características estéticas variadas. Há a presença da cor vermelha na impressão, além do preto. Em duas das capas predomina a composição centralizada com título em vermelho. Na capa do meio existem grafismos lineares que subdividem o espaço, deslocando a mancha gráfica mais para a lateral esquerda, o vermelho aparece nas letras iniciais e o título têm tamanhos diferentes para cada grupo de palavras. As características comuns entre estas três capas são a utilização de tipografias sem serifas, o uso pontual do vermelho nos títulos e a forma de distribuição das informações essenciais na capa, utilizando principalmente maiúsculas, ocupando as áreas de cabeçalho com autoria, área central com título da obra e rodapé com a cidade e o ano de impressão.

Estas publicações encontradas não se assemelham diretamente às características estéticas dos catálogos da Pinacoteca que, diante destas publicações, parecem possuir um layout planejado especialmente para a Pinacoteca, apresentando traços de documento oficial.

\section{CONSIDERAÇÕES SOBRE OS CATÁLOGOS DA DÉCADA DE 1940}

Nos materiais gráficos pertencentes à década de 1940 analisados fica visualmente evidente a importância conferida ao vínculo da Pinacoteca com o Estado. Nestas publicações o uso do brasão das Armas Nacionais reforça este vínculo, ocupando posição de destaque na estrutura gráfica das capas dos catálogos de obras de arte.

Nos catálogos que datam de 1940 e 1942 a assinatura gráfica da Pinacoteca integra a composição do título da publicação, e seu nome, em destaque, aparece descrito "Catálogo da Pinacoteca do Estado de S. Paulo" na publicação de 1940 e "Catálogo da Pinacoteca do Estado de S. Paulo Brasil" na de 1942.

As publicações da Pinacoteca pela Gráfica Paulista de João Bentivegna, juntamente com outras publicações da mesma gráfica encontradas em um recorte posterior, abrangendo a década de 1950, sugerem que a gráfica prestava serviços ao Governo do Estado, vínculo que pode ter se estendido ao menos pelo período de duas décadas se observadas as publicações de catálogos da Pinacoteca que datam de 1950, 1951 e 1954, também assinadas pela gráfica de João Bentivegna, e serão analisadas em um próximo artigo.

\section{REFERÊNCIAS}

A BANDEIRA e símbolos nacionais. Col. Educação Moral e Civica, 1. Santos: Diário Oficial do Município, 1970.

AMARAL, A. Aracy. Textos do Trópico de Capricórnio - vol. 2. Artigos e ensaios (19802005): Circuitos de arte na América Latina e no Brasil. São Paulo: Editora 34, 2006.

ARAGÃO, Isabella. Um breve panorama dos catálogos de tipos das fundidoras Funtimod e Manig. In: Anais do 9o Congresso Brasileiro de Pesquisa e 
Desenvolvimento em Design 2010. São Paulo: PPG em Design | Universidade Anhembi Morumbi, AEND-Brasil, 2010.

ARAUJO, Marcelo Matos; CAMARgOS, Marcia. (Orgs.). Pinacoteca: a história da Pinacoteca do Estado de São Paulo. [Pinacoteca do Estado: a história de um museu]. São Paulo: Artemeios, 2007.

BRASIL. Lei $n$ ㅇ 5.443, de 28 de maio de 1968. Dispõe sobre a forma e a apresentação dos Símbolos Nacionais, e dá outras providências. Publicado originalmente em: Diário Oficial [da República Federativa do Brasil], Brasília, DF, 31 mai. 1968. Seção I, p. 1. Disponível em: <http://legis.senado.gov.br/legislacao/ListaNormas.action?numero= 5443\&tipo_norma=LEI\&data=19680528\&link=s>. Acesso em: 20 de maio, 2016.

CAMARGOS, Marcia; MORAES, Maria Luiza. Pinacoteca do Estado de São Paulo, 18852005, Cronologia in 100 Anos da Pinacoteca: A formação de um acervo. São Paulo: Pinacoteca do Estado de São Paulo, 2005.

CORDEIRO, Jose Pedro Leite. São Paulo e a invasão holandesa no Brasil / Jose Pedro Leite Cordeiro. São Paulo: Bentivegna, 1949. 244 p. Acervo da Biblioteca Octávio Ianni / Instituto de Filosofia e Ciências Humanas, Unicamp.

FARIAS, Priscila. On graphic memory as a strategy for design history. In: Proceedings of the $9^{\text {th }}$ Conference of the International Committee for Design History and Design Studies, p. 201-206. São Paulo: Blucher, 2014. Disponível em $<$ http://www.proceedings.blucher.com.br/article-details/on-graphic-memory-as-astrategy-for-design-history-13838>.

FEDERICI, Hilton. Simbolos paulistas: (estudo historico-heraldico). São Paulo, SP: Conselho Estadual de Artes e Ciencias Humanas, 1980.

GORDINHO, Margarida Cintra. Gráfica: Arte e Indústria no Brasil: 180 anos de história. São Paulo: Bandeirante Editora, 1991.

GOVERNO do Estado de São Paulo; Secretaria da Cultura; Pinacoteca do Estado de São Paulo. Guia de fundos e coleções do Acervo Arquivístico: Edição comemorativa dos 10 anos do Cedoc e 110 anos da Pinacoteca. São Paulo: 2015. Disponível em:

$<$ http://biblioteca.pinacoteca.org.br:9090/local/File/guia cedoc.pdf $>$. Acesso em: Ago. 2015.

HALLEWEL, Laurence. O livro no Brasil: sua história. 2. Ed. São Paulo: Editora da Universidade de São Paulo, 2005.

LIMA, Paula Garcia; MICHELON, Francisca Ferreira. 2010. As peças gráficas do Parque Souza Soares (Pelotas,1900-1930): algumas relações entre design e memória. In: 9o Congresso Brasileiro de Pesquisa e Desenvolvimento em Design. São Paulo (SP): Anhembi Morumbi, 1206-1216, 2010.

LUZ, Milton. A historia dos símbolos nacionais: a bandeira, o brasão, o selo, o hino. Brasília, DF: Senado Federal/Secretaria Especial de Editoração e Publ., 1999. 169 p., il. MARINGELLI, Isabel C. A. S.; BEVILACQUA, Gabriel M. F. 100 anos de edição gráfica da Pinacoteca do Estado: 1912-2012. São Paulo: Pinacoteca do Estado de São Paulo, 2013. 
MOTTA, Cassio. Cesario Motta e seu tempo. São Paulo: João Bentivegna, 1947. 255p., il. Coleção Oficina do Livro: Acervo de coleções Especiais e Obras Raras / Biblioteca Central César Lattes, Unicamp.

OLIVEIRA, Sebastião Almeida. Garcia Redondo. São Paulo: João Bentivegna, 1942. Acervo de coleções Especiais e Obras Raras / Biblioteca Central César Lattes, Unicamp (não catalogado, 2015).

PIAIA, Jade S.; PFÜTZENREUTER, Edson P. 2015. Identidade visual dos primeiros catálogos da Pinacoteca: relações históricas. In: C. G. Spinillo; L. M. Fadel; V. T. Souto; T. B. P. Silva \& R. J. Camara (Eds). Anais [Oral] do 7o Congresso Internacional de Design da Informação/Proceedings [Oral] of the 7th Information Design International Conference | CIDI 2015 [Blucher Design Proceedings, num.2, vol.2]. São Paulo: Blucher, 2015. ISSN 2318-6968, ISBN: 978-85-8039-122-0. DOI 10.5151/designproCIDI2015-cidi_59. Disponível em: <http://pdf.blucher.com.br.s3-sa-east-

1.amazonaws.com/designproceedings/cidi2015/cidi_59.pdf>. Acesso em: 01 de set., 2016.

PIAIA, Jade S. Ficha de coleta de dados | Assinatura gráfica da Pinacoteca 1912-1965 catálogos (respostas). Campinas, 2016. (Documento do "Google Drive"). Disponível em: <https://docs.google.com/spreadsheets/d/1dObxeWDfFBpIQhQ1Un1jLOBWpNLOkuaGLqxaWPiXDA/edit?usp=sharing >. Acesso em: 20/05/2016.

PINACOTECA DO ESTADO. Catálogo. São Paulo: Gráfica Paulista, 1940. Acervo Cedoc /Pinacoteca do Estado de São Paulo.

. Catálogo. São Paulo: Gráfica Paulista, 1942. Acervo Cedoc /Pinacoteca do Estado de São Paulo.

Documento timbrado. Secretaria de Estado dos Negócios da Educação e Saúde Pública, Pinacoteca do Estado de São Paulo, 1943. Original fotografado. Acervo Cedoc / Pinacoteca do Estado de São Paulo.

SALOMON, Carlos A. X.; GOUVEIA, Anna Paula S.; FARIAS, Priscila L.. Fichas de pesquisa de campo para estudo da tipografia nominativa na arquitetura carioca. In: InfoDesign: Revista Brasileira de Design da Informação 6 - 2, p. 7-15, 2009.

TONINI, J. C.; PAIVA, R. M.; TORRES, L. C.; DUTRA, T. L. M.; FONSECA, L. P.; PACHECO, S. H. Desenvolvimento da "Ficha de Coleta de Dados" para análise gráfica da revista Vida Capichaba. In: 9o Congresso Brasileiro de Pesquisa e Desenvolvimento em Design. São Paulo (SP): Anhembi Morumbi, 2186-2191, 2010.

TWYMAN, Michael. A schema for the study of graphic language. In: kolers, Paul; wrolstad, Merald \& bouma, Herman (Eds.). Processing of visible language. New York: Plenum Press, v.1, p. 117-150, 1979.

VILLAS-BOAS, André. Sobre Análise gráfica, ou Algumas estratégias didáticas para a difusão de um design crítico. Arcos Design. n. 5. Dez, 2009. p. 2-17.

WILLE, D. N.; SOUZA, H. P.; SILVA, M. B. M.; FERREIRA, M. M.; IGANSI, J. F. Análise Gráfica dos Anúncios "Elixir de Nogueira" publicados no "Almanach de Pelotas" de 1913 a 1918. In: 9o Congresso Brasileiro de Pesquisa e Desenvolvimento em Design. São Paulo (SP): Anhembi Morumbi, 1593-1598, 2010. 